\title{
Knowledge, Practice and Self-Efficacy in Evidence-Based Practice among Midwives in East Iran
}

"Elham Azmoude, ${ }^{1}$ Fereshteh Farkhondeh, ${ }^{2}$ Maryam Ahour, ${ }^{2}$ Maryam Kabirian ${ }^{1}$

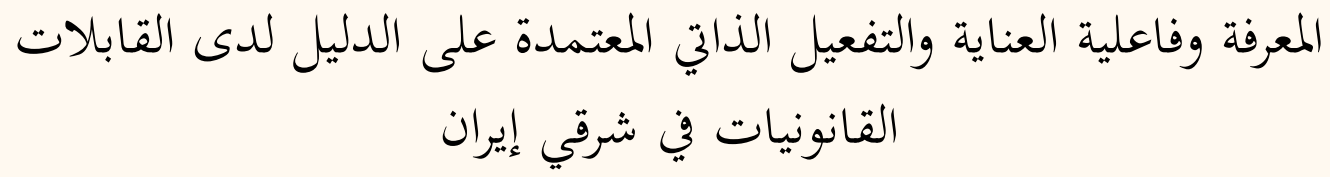

الهام آزموده، فرشته فرخنده، مريم آهور، مريم كابيريان

ABSTRACT: Objectives: The successful implementation of evidence-based practice (EBP) can lead to appropriate and effective midwifery care during pregnancy, childbirth and in the postnatal period. However, levels of knowledge and confidence in one's ability to apply EBP are related to its effective implementation. This study aimed to investigate levels of knowledge, practice of and self-efficacy towards the use of EBP among midwives in East Iran. Methods: This cross-sectional study took place between January and February 2016 and involved 98 midwives employed at two hospitals and all four urban health care centres in Torbat-e Heydariyeh, Iran. Two subscales of the Evidence-Based Practice Questionnaire were used to assess participants' knowledge and practice of EBP, respectively, while a modified version of a previously described scale was used to determine self-efficacy. Results: A total of 76 midwives participated in the study (response rate: 77.6\%). Mean knowledge, practice and self-efficacy scores were $4.48 \pm 0.94,3.53 \pm 0.68$ and $2.80 \pm 0.81$, respectively. Significant relationships were found between mean selfefficacy, practice and knowledge scores and proficiency in English language $(P=0.001$ each) and statistical methods $(P<0.050$ each). Additionally, significant relationships were found between knowledge and practice of EBP and proficiency in the use of databases $(P<0.050$ each). Knowledge and self-efficacy scores were significantly correlated with practice $(P=0.001$ each). Conclusion: These findings demonstrate a need for improvement in the self-efficacy, practice and knowledge of EBP among midwives in East Iran. Interventions that promote these factors may help increase the use of EBP in this population.

Keywords: Evidence-Based Practice; Knowledge; Self Efficacy; Nurse Midwives; Iran.

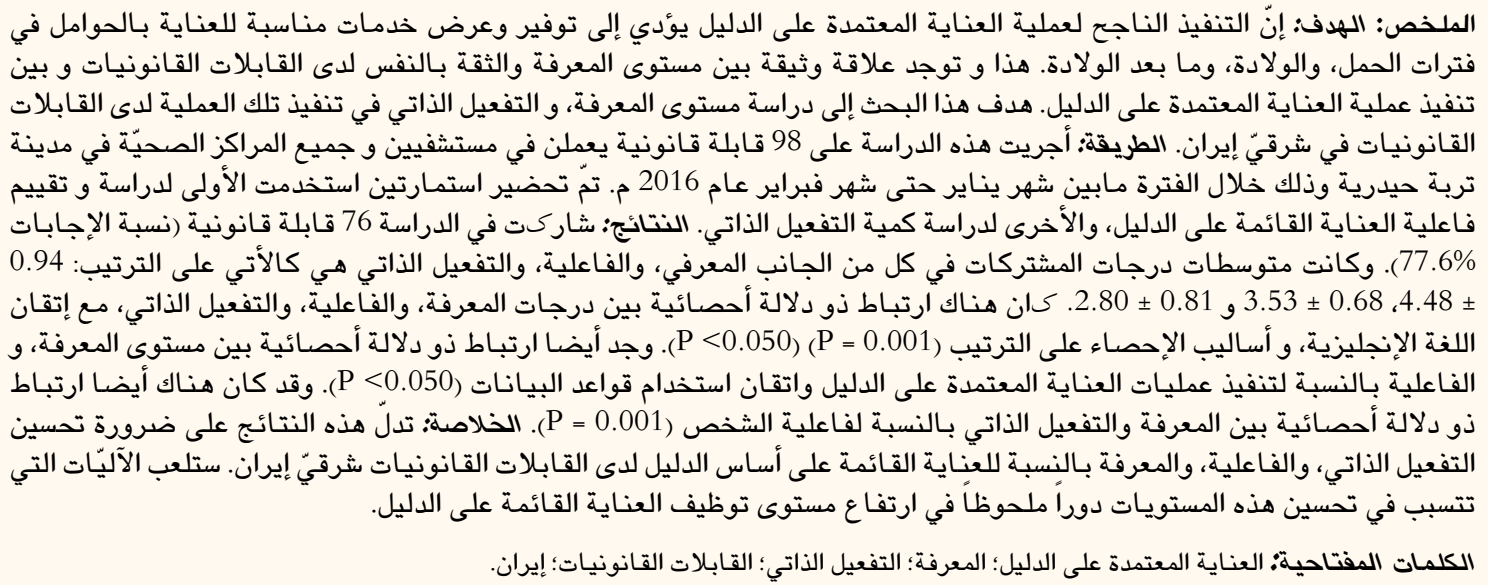

\section{AdVANCES IN KNOWLEDGE}

The findings of this study indicate that midwives in East Iran have poor levels of practice and moderate levels of knowledge and selfefficacy regarding evidence-based practice (EBP).

Significant relationships were observed between EBP knowledge, practice and self-efficacy and proficiency in English, statistical methods and using databases. Knowledge and self-efficacy were also significantly correlated with practice. 


\section{Application to Patient Care}

The implementation of EBP is a vital competency for midwives. The moderate levels of EBP knowledge and self-efficacy and poor levels of practice reported among the Iranian midwives in the current study have alarming implications for future patient care. As such, interventions to promote EBP implementation are recommended in this population.

$\mathrm{P}$ REGNANCY-RELATED COMPLICATIONS ARE THE second global leading cause of death among women of reproductive age. ${ }^{1}$ In 2015 , approximately 303,000 maternal deaths occurred worldwide, most of which could have been prevented; in the same year, 340 women in Iran died from pregnancyrelated complications, resulting in a maternal mortality ratio of 25 deaths per 100,000 live births. ${ }^{2}$ Evidence-based practice (EBP) plays an integral role in high-quality healthcare by promoting a problemsolving approach that emphasises implementation of the current best available research within a clinical context, helping healthcare professionals to remain up-to-date and make better healthcare decisions. ${ }^{3-7}$ The National Academy of Medicine in the USA recognises EBP as an essential skill for healthcare providers in the $21^{\text {st }}$ century. ${ }^{8}$ Several studies have also indicated that EBP improves the quality and safety of patient care. ${ }^{6,7,9}$

Nevertheless, many healthcare decisions are still based on traditional practices, assumptions, personal experiences and individual opinions and skills. ${ }^{10,11}$ The possession of adequate knowledge and skills is essential for gathering and appraising evidence and implementing best practices in a clinical setting. ${ }^{4}$ However, numerous studies have revealed that most healthcare professionals do not have sufficient knowledge and skills for the effective implementation of EBP.,11-14 In a study analysing perceptions of EBP among nurses, Melnyk et al. found that fewer than half of the participants believed that their colleagues consistently used EBP in patient care. ${ }^{5}$ Similarly, Zhou et al. indicated that most Chinese nurses lacked practice in many EBP-related skills. ${ }^{15}$ Another important variable affecting the implementation of EBP is self-efficacy, which is defined as an individual's belief in their own ability to execute skills at a designated level of performance. ${ }^{11,16-18}$ Several studies have indicated that the majority of healthcare professionals do not have the desired level of selfefficacy in the implementation of EBP. ${ }^{11,19}$

To the best of the authors' knowledge, few studies have focused on the knowledge, practice and selfefficacy of EBP among Iranian midwives. As health policies in Iran are based on population growth, the role of midwives is becoming more prominent, due to their importance in the pregnancy and childbirth process. This study therefore aimed to determine levels of knowledge, practice and self-efficacy towards EBP in clinical decision-making among midwives working in hospitals and healthcare centres in Torbat-e Heydariyeh, Iran.

\section{Methods}

This descriptive cross-sectional study took place from January to February 2016 and included 98 midwives employed at two public hospitals and all four urban health centres in Torbat-e Heydariyeh. Only those midwives with at least six months of work experience at the time of the study were included. Midwives who were sick or on maternity leave during this period were excluded from the study. A convenience sampling method was used to recruit the midwives. All midwives in the hospitals and health centres were informed of the study goals and were invited to participate at the beginning of each work shift.

A questionnaire was designed to collect information regarding the participants' sociodemographic and professional characteristics, including age, education level, number of years of work experience, previous participation in EBP courses, proficiency in English, statistical methods and use of databases, participation in conferences or congresses and number of previously published articles in national and international journals. The frequency of use of various print (five items), electronic (eight items) or human (six items) health information sources was scored on a 5-point Likert scale, with a score of 1 indicating never and 5 indicating always. ${ }^{11}$ In order to assess EBP knowledge and practice, the 14-item and 6-item subscales of the Evidence-Based Practice Questionnaire were used; items were scored on 7-point Likert scales ranging from 1 to 7 , indicating poor and best knowledge for knowledge items and never and frequently for practice items, respectively. ${ }^{20} \mathrm{~A}$ modified version of a previously described EBP self-efficacy scale was used to determine the participants' self-efficacy towards implementing EBP. ${ }^{11}$ These eight items were scored on a 5-point Likert scale, with scores of 1 and 5 indicating poor and best efficacy, respectively. ${ }^{11}$

All of the questionnaire items were translated from the original English into Persian, after which two linguists made revisions to ensure the validity of the translations. Subsequently, the content and face validity of all questionnaire items was confirmed by 
Table 1: Sociodemographic and professional characteristics of midwives in Torbat-e Heydariyeh, $\operatorname{Iran}(\mathrm{N}=76)$

\begin{tabular}{|c|c|}
\hline Characteristic & n (\%) \\
\hline \multicolumn{2}{|c|}{ Experience in years* } \\
\hline$<5$ & $39(51.3)$ \\
\hline $5-10$ & $27(35.5)$ \\
\hline$>10$ & $9(11.8)$ \\
\hline \multicolumn{2}{|c|}{ Previous participation in EBP courses } \\
\hline Yes & $34(44.7)$ \\
\hline No & $42(55.3)$ \\
\hline \multicolumn{2}{|c|}{ Proficiency in English } \\
\hline Low & $25(32.9)$ \\
\hline Moderate & $48(63.2)$ \\
\hline High & $3(3.9)$ \\
\hline \multicolumn{2}{|c|}{ Proficiency with statistical methods* } \\
\hline None & $14(18.4)$ \\
\hline Low & $37(48.7)$ \\
\hline Moderate & $22(28.9)$ \\
\hline High & $2(2.6)$ \\
\hline \multicolumn{2}{|c|}{ Proficiency in database use ${ }^{+}$} \\
\hline None & $3(3.9)$ \\
\hline Low & $22(28.9)$ \\
\hline Moderate & $41(53.9)$ \\
\hline High & $6(7.9)$ \\
\hline \multicolumn{2}{|c|}{ Previous participation in conferences or congresses } \\
\hline Yes & $58(76.3)$ \\
\hline No & $18(23.7)$ \\
\hline \multicolumn{2}{|c|}{$\begin{array}{l}\text { Number of previously published articles in } \\
\text { national journals* }\end{array}$} \\
\hline 0 & $66(86.8)$ \\
\hline $1-2$ & $3(3.9)$ \\
\hline$\geq 3$ & $6(7.9)$ \\
\hline \multicolumn{2}{|c|}{$\begin{array}{l}\text { Number of previously published articles in } \\
\text { international journals }\end{array}$} \\
\hline 0 & $73(96.1)$ \\
\hline 1 & $1(1.3)$ \\
\hline$\geq 2$ & $2(2.6)$ \\
\hline
\end{tabular}

*Due to missing data in the completed questionnaire of one participant, the total cohort for this variable was $75 .{ }^{\dagger}$ Due to missing data in the completed questionnaires of four participants, the total cohort for this variable was 72. a group of experts. Additionally, Cronbach's alpha values indicated good internal consistency reliability of the knowledge (0.81), self-efficacy (0.88), practice (0.70), print information sources (0.72) electronic information sources (0.88) and human information sources (0.72) questionnaire items. The various questionnaire subscales were compiled into one survey which was distributed individually to each midwife. The researchers then collected the completed surveys from midwives at each hospital and healthcare centre. The entire survey took approximately 15 minutes to complete.

Data were analysed using the Statistical Package for the Social Sciences (SPSS), Version 19.0 (IBM Corp., Chicago, Illinois, USA). Means, standard deviations and frequencies were calculated for the descriptive data. To determine relationships between variables, Pearson and Spearman's correlation tests were performed. A $P$ value of $<0.050$ was considered statistically significant.

This study was approved by the Ethical Board Committee of Torbat Heydariyeh University of Medical Sciences (\#IR.THUMS.REC.1394.2). All of the midwives provided written informed consent before participating in the study. Midwives were assured of the confidentiality of the data before recruitment. Once analysed, the results of this study were provided to the midwives and officials of the participating health centres and hospitals.

\section{Results}

A total of 76 midwives participated in the study (response rate: 77.6\%); of these, 42 (55.3\%) were employed by hospitals and $34(44.7 \%)$ by health centres. The mean age of the participants was $29.30 \pm 4.86$ years (range: $22-43$ years old). The percentage of midwives with a bachelor's or master's qualification was $93.4 \%$ and $6.6 \%$, respectively. The mean number of years of work experience was $5.22 \pm 4.21$ years (range: 6 months -18 years). Overall, $44.7 \%$ of the midwives had previously taken part in EBP training courses. Most of the participants were moderately proficient in English (63.2\%) but had low proficiency in statistics (48.7\%) [Table 1].

Mean knowledge, practice and self-efficacy scores were $4.48 \pm 0.94,3.53 \pm 0.68$ and $2.80 \pm 0.81$, respectively. Mean scores for individual items in the knowledge subscale ranged from 3.78-5.29. Determining the validity and usefulness of material were the knowledge items with the lowest mean 
Table 2: Knowledge of evidence-based practice* among midwives in Torbat-e Heydariyeh, Iran $(\mathrm{N}=76)$

\begin{tabular}{|c|c|}
\hline Questionnaire item & $\begin{array}{l}\text { Mean score } \\
\quad \pm \text { SD }\end{array}$ \\
\hline $\begin{array}{l}\text { Converting information queries into a } \\
\text { question }\end{array}$ & $4.21 \pm 1.56$ \\
\hline Research skills & $4.06 \pm 1.40$ \\
\hline Awareness of information types/sources & $4.45 \pm 1.28$ \\
\hline Ability to determine the validity of material & $3.78 \pm 1.36$ \\
\hline Ability to critically appraise material & $4.05 \pm 1.29$ \\
\hline Knowledge of how to retrieve evidence & $4.20 \pm 1.34$ \\
\hline IT skills & $4.24 \pm 1.34$ \\
\hline Monitoring and reviewing practice skills & $4.44 \pm 1.39$ \\
\hline Ability to identify gaps in own practice & $4.44 \pm 1.33$ \\
\hline Ability to determine usefulness of material & $3.97 \pm 1.36$ \\
\hline Discussion of new ideas with colleagues & $5.08 \pm 1.14$ \\
\hline $\begin{array}{l}\text { Application of information to individual } \\
\text { cases }\end{array}$ & $5.25 \pm 1.18$ \\
\hline Sharing ideas/information with colleagues & $5.29 \pm 1.20$ \\
\hline Ability to review own practice & $5.26 \pm 1.27$ \\
\hline \multicolumn{2}{|l|}{$S D=$ standard deviation; $I T$ = information technology. } \\
\hline
\end{tabular}

scores $(3.78 \pm 1.36$ and $3.97 \pm 1.36$, respectively) [Table 2]. In the self-efficacy subscale, mean scores ranged from 3.26-3.88, indicating that the midwives had above-average self-efficacy. However, conversion of a clinical problem into a well-formulated clinical question resulted in a lower mean self-efficacy score in comparison to the other items $(3.26 \pm 0.98)$ [Table 3]. For the practice subscale, mean scores ranged from 3.94-4.97. The most practiced items included sharing information with colleagues $(4.97 \pm 1.53)$, integrating evidence with expertise $(4.67 \pm 1.30)$ and formulating clear questions (4.43 \pm 1.42$)$, whereas critically appraising literature was the least frequently practised item $(3.94 \pm 1.34)$ [Table 4].

In terms of health information sources, print sources were most frequently employed, closely followed by electronic sources (3.43 \pm 0.86 and $3.13 \pm 0.97$, respectively). Among print information resources, textbooks and instructions/handouts produced by the Iranian Ministry of Health $(\mathrm{MOH})$ were the most frequently used $(3.96 \pm 1.15$ and $3.92 \pm 1.06$, respectively). Websites identified via an Internet browser search engine were the most frequently used electronic source (3.50 \pm 1.43), followed by online tutorials provided by professional associations, medical libraries or overseas hospitals
Table 3: Self-efficacy towards evidence-based practice* among midwives in Torbat-e Heydariyeh, Iran $(\mathrm{N}=76)$

$\begin{array}{lc}\begin{array}{l}\text { Questionnaire item } \\ \text { Ability to identify clinical problems }\end{array} & \begin{array}{c}\text { Mean score } \\ \pm \text { SD }\end{array} \\ \begin{array}{l}\text { Ability to overcome barriers of evidence- } \\ \text { based care }\end{array} & 3.88 \pm 0.92 \\ & \\ \text { Ability to convert a clinical problem into a } & 3.26 \pm 0.78 \\ \text { well-formulated clinical question } & \\ \begin{array}{l}\text { Ability to conduct online searches using } \\ \text { databases and web search engines }\end{array} & 3.55 \pm 1.01 \\ \begin{array}{l}\text { Ability to relate research findings to clinical } \\ \text { practice and point out similarities and } \\ \text { differences when reading research articles }\end{array} & 3.57 \pm 0.91 \\ \begin{array}{l}\text { Ability to read research reports and form } \\ \text { general notions of strengths and weaknesses }\end{array} & 3.57 \pm 0.91 \\ \begin{array}{l}\text { Ability to apply interventions based on the } \\ \text { most applicable evidence }\end{array} & 3.44 \pm 0.87 \\ \begin{array}{l}\text { Ability to evaluate the application of } \\ \text { interventions and use this to improve } \\ \text { clinical decisions }\end{array} & 3.51 \pm 0.96 \\ \begin{array}{l}\text { SD }=\text { standard deviation. } \\ \text { "Self-efficacy was self-assessed by participants using a Persian version } \\ \text { of a previously described evidence-based practice self-efficacy scale."1 } \\ \text { Responses were scored on a 5-point Likert scale, with scores of } 1 \text { and } 5 \\ \text { indicating poor and best efficacy, respectively. }\end{array}\end{array}$

Table 4: Practice of evidence-based practice* among midwives in Torbat-e Heydariyeh, Iran $(\mathrm{N}=76)$

$\begin{array}{lc}\text { Item } & \begin{array}{c}\text { Mean score } \\ \pm \text { SD }\end{array} \\ \begin{array}{l}\text { Critical appraisal of literature } \\ \text { Integration of evidence with expertise }\end{array} & 3.94 \pm 1.34 \\ & 4.67 \pm 1.30 \\ \text { Formulation of clear questions } & 4.43 \pm 1.42 \\ \text { Tracking down of relevant evidence } & 4.39 \pm 1.47 \\ \text { Evaluation of outcomes of practice } & 4.36 \pm 1.41 \\ \text { Sharing of information with colleagues } & 4.97 \pm 1.53 \\ & \\ \begin{array}{l}\text { SD = standard deviation. } \\ \text { *Practice was self-assessed by participants using a Persian version of } \\ \text { the practice subscale of the Evidence-Based Practice Questionnaire. }\end{array} \\ \begin{array}{l}\text { Responses were scored on a 7-point Likert scale, with scores of } 1 \text { and } 7 \\ \text { indicating never and frequently, respectively. }\end{array}\end{array}$

(3.36 \pm 1.28). Finally, the most common human sources of health information were colleagues $(3.41 \pm 1.27)$ and physicians $(3.32 \pm 1.24)$ [Table 5].

A bivariate correlational analysis was performed to determine relationships between EBP knowledge, self-efficacy and practice scores and the demographic and professional characteristics of the midwives. Significant relationships were observed between education level and knowledge, self-efficacy and practice $(P=0.001,0.010$ and 0.013 , respectively). Moreover, significant correlations between knowledge, self-efficacy and practice were observed with 
Table 5: Frequency of use of health information sources" among midwives in Torbat-e Heydariyeh, Iran $(\mathrm{N}=76)$

\begin{tabular}{|c|c|}
\hline Source of information & $\begin{array}{l}\text { Mean score } \\
\quad \pm \text { SD }\end{array}$ \\
\hline Print & $3.43 \pm 0.86$ \\
\hline Textbooks & $3.96 \pm 1.15$ \\
\hline Journal articles & $3.05 \pm 1.27$ \\
\hline Magazines/newspapers & $2.96 \pm 1.46$ \\
\hline $\begin{array}{l}\text { Instructions/handouts from the Iranian } \\
\mathrm{MOH}\end{array}$ & $3.92 \pm 1.06$ \\
\hline Other & $3.16 \pm 1.13$ \\
\hline Electronic & $3.13 \pm 0.97$ \\
\hline E-books & $3.20 \pm 1.30$ \\
\hline Digital medical/nursing libraries & $2.81 \pm 1.30$ \\
\hline Medical/nursing databases (e.g. CINAHL) & $3.11 \pm 1.36$ \\
\hline Websites found via browser search engines & $3.50 \pm 1.43$ \\
\hline Online tutorials & $3.36 \pm 1.28$ \\
\hline Medical blogs & $2.92 \pm 1.18$ \\
\hline $\begin{array}{l}\text { UpToDate (Wolters Kluwer Health, Alphen } \\
\text { aan den Rijn, Netherlands) and ClinicalKey } \\
\text { (Elsevier, Amsterdam, Netherlands) } \\
\text { databases }\end{array}$ & $2.92 \pm 1.24$ \\
\hline Other & $2.97 \pm 1.37$ \\
\hline Human & $3.01 \pm 1.05$ \\
\hline Colleagues & $3.41 \pm 1.27$ \\
\hline Supervisors & $2.82 \pm 1.36$ \\
\hline Research groups within an organisation & $2.72 \pm 1.32$ \\
\hline Physicians & $3.32 \pm 1.24$ \\
\hline $\begin{array}{l}\text { Professional friends working in other } \\
\text { hospitals/clinics }\end{array}$ & $2.98 \pm 1.24$ \\
\hline Other & $2.92 \pm 1.31$ \\
\hline \multicolumn{2}{|c|}{$\begin{array}{l}S D=\text { standard deviation; } M O H=\text { Ministry of Health; } \\
C I N A H L=\text { Cumulative Index to Nursing and Allied Health Literature. }\end{array}$} \\
\hline $\begin{array}{l}\text { "Frequency of use of health information sources } \\
\text { by participants using a Persian version of a previc } \\
\text { questionnaire." Responses were scored on a 5-poi }\end{array}$ & $\begin{array}{l}\text { lf-assessed } \\
\text { described } \\
\text { kertscale, with } \\
\text { vely. }\end{array}$ \\
\hline
\end{tabular}

proficiency in English $(P=0.001$ each) and statistical methods $(P=0.002,0.016$ and 0.015 , respectively). Similarly, knowledge and practice had statistically significant relationships with proficiency in the use of databases $(P=0.015$ and 0.005 , respectively). Midwives with a higher number of published articles in national journals also had significantly higher self-efficacy scores $(P=0.023)$. No correlation was noted between previous EBP training and knowledge, self-efficacy or practice. Finally, significant relationships were found between mean knowledge scores and self-efficacy and practice $(P=0.001$ each) and between mean self- efficacy scores and practice $(P=0.001)$ [Table 6].

\section{Discussion}

Overall, different levels of EBP knowledge, practice and self-efficacy have been reported among health professionals. ${ }^{6,11,21,22}$ These findings may be useful in developing a comprehensive and appropriate strategy for promoting EBP, leading to more effective patient care. ${ }^{23}$ In the current study, levels of knowledge and self-efficacy among the midwives were slightly higher than average, while their practice scores were below average. Previous research has also demonstrated moderate mean knowledge scores among nurses and nursing faculty. ${ }^{5,13,24,25}$ Brown et al. reported that practice scores among nurses were higher than average while Farokhzadian et al. previously reported a low mean self-efficacy score among nurses $(2.93 \pm 1.06) .{ }^{19,24}$ Appropriate interventions should be performed targeting priorities among the items in the three subscales utilised in the current study to increase knowledge and practice of and self-efficacy towards EBP among midwives in East Iran. As per the findings of the present study, the ability to determine the validity (i.e. truthfulness) and usefulness (i.e. clinical application) of information should have the highest priority in the knowledge context when planning an intervention. Consequently, midwives should be able to identify reliable and applicable information within a large volume of medical research in order to bridge the gap between empirical evidence and clinical practice.

Participants of the current study demonstrated the least self-efficacy when it came to their ability to convert a clinical problem into a well-formulated question and to apply an intervention based on the most applicable evidence. Similarly, Mohsen et al. found that most clinical nurse specialists had no confidence in their ability to translate clinical problems into well-formulated questions. ${ }^{26}$ The ability to apply interventions based on the most applicable evidence was also one of the highest priorities identified in another Iranian study. ${ }^{19}$ In general, EBP should begin with a precise and structured clinical question; it is therefore important that midwives develop the necessary skills to convert informational needs into questions. Subsequently, evidence can be applied to a clinical decision. ${ }^{27}$ In the current study, mean scores for the remaining self-efficacy items were comparable, indicating moderate levels of confidence among the midwives for other aspects of EBP self-efficacy. Other studies have reported mean self-efficacy scores of 2.5-3.5 among nurses. ${ }^{11,19}$

In terms of mean practice scores, results from the current study indicated that the ability to critically 
Table 6: Correlations between demographic and professional characteristics and evidence-based practice knowledge, self-efficacy and practice scores* among midwives in Torbat-e Heydariyeh, Iran $(\mathrm{N}=76)$

\begin{tabular}{|c|c|c|c|c|c|c|}
\hline \multirow[t]{2}{*}{ Variable } & \multicolumn{2}{|c|}{ Knowledge } & \multicolumn{2}{|c|}{ Self-efficacy } & \multicolumn{2}{|c|}{ Practice } \\
\hline & $\mathbf{r}$ & $P$ & $\mathbf{r}$ & $P$ & $\mathbf{r}$ & $P$ \\
\hline Age & 0.086 & 0.468 & 0.130 & 0.297 & 0.246 & $0.036^{\ddagger}$ \\
\hline Education level & 0.369 & $0.001^{\ddagger}$ & 0.314 & $0.010^{\ddagger}$ & 0.289 & $0.013^{\ddagger}$ \\
\hline Work experience & 0.082 & 0.489 & 0.151 & 0.228 & 0.170 & 0.150 \\
\hline Previous EBP training & 0.142 & 0.224 & -0.070 & 0.572 & 0.191 & 0.102 \\
\hline Proficiency in English & 0.419 & $0.001^{\ddagger}$ & 0.423 & $0.001^{\ddagger}$ & 0.410 & $0.001^{\ddagger}$ \\
\hline Proficiency in statistics & 0.354 & $0.002^{\ddagger}$ & 0.294 & $0.016^{\ddagger}$ & 0.285 & $0.015^{\ddagger}$ \\
\hline Proficiency in the use of databases & 0.288 & $0.015^{\ddagger}$ & 0.215 & 0.088 & 0.329 & $0.005^{\ddagger}$ \\
\hline Previous participation in conferences/congresses & 0.153 & 0.190 & 0.103 & 0.408 & 0.140 & 0.233 \\
\hline Number of published articles in national journals & 0.113 & 0.339 & 0.280 & $0.023^{\ddagger}$ & 0.056 & 0.638 \\
\hline Number of published articles in international journals & 0.191 & 0.100 & 0.203 & 0.100 & 0.088 & 0.458 \\
\hline Print information sources ${ }^{\dagger}$ & 0.384 & $0.008^{\ddagger}$ & 0.464 & $0.002^{\ddagger}$ & 0.386 & $0.009^{\ddagger}$ \\
\hline Electronic information sources ${ }^{\dagger}$ & 0.274 & 0.066 & 0.261 & 0.099 & 0.265 & 0.075 \\
\hline Human information sources ${ }^{\dagger}$ & -0.077 & 0.593 & 0.160 & 0.292 & -0.080 & 0.586 \\
\hline Knowledge score & - & - & 0.625 & $0.001^{\ddagger}$ & 0.739 & $0.001^{\ddagger}$ \\
\hline Self-efficacy score & - & - & - & - & 0.638 & $0.001^{\ddagger}$ \\
\hline
\end{tabular}

$E B P=$ evidence-based practice.

*Knowledge and practice were self-assessed by participants using Persian versions of the knowledge and practice subscales of the Evidence-Based Practice Questionnaire while self-efficacy was self-assessed by participants using a Persian version of a previously described EBP self-efficacy scale. 11,20 ${ }^{+}$Frequency of use of health information sources was self-assessed by participants using a Persian version of a previously described questionnaire. ${ }^{11}$ ${ }^{\ddagger}$ Significant at $P<0.050$.

appraise literature, evaluate outcomes of practice and track down relevant evidence were the most important priorities for an EBP intervention among midwives in East Iran. These findings are consistent with those of Shafiei et al. and Brown et al..$^{24,25}$ Therefore, educational interventions would be useful to familiarise midwives with the entire EBP process, from formulating answerable questions to finding recent and relevant material, critically evaluating evidence and applying that evidence in practice.

In the current study, midwives with a higher level of education had significantly greater knowledge, self-efficacy and practice of EBP. This may be because midwives with more advanced academic degrees had more knowledge and experience in practicing EBP and were therefore more likely to be confident in their EBP skills. Farokhzadian et al. observed no significant relationship between self-efficacy and academic degree in another study of Iranian nurses; in contrast, Weng et al. also reported that healthcare professionals with more advanced academic degrees more frequently implemented EBP. ${ }^{12,19}$ Similarly, several studies have confirmed the positive effects of higher education levels on patient outcomes through the implementation of EBP. ${ }^{26,28-30}$ In the present study, midwives who were older and had more work experience were not significantly more likely to have greater EBP knowledge, self-efficacy or practice. This finding was supported by a previous study which found no relationships between age or clinical experience with EBP knowledge among nurses. ${ }^{13}$ However, both Majid et al. and Ferguson et al. have suggested that new nurses have limited practical knowledge and experience and are less confident in the implementation of EBP. ${ }^{11,31}$ Nearly half of the participants in the current study reported previously taking part in EBP training courses; however, relationships between this variable and EBP knowledge, practice or self-efficacy were not significant, which is inconsistent with previous findings from Iran and Singapore. ${ }^{11,19}$

Significant relationships were noted in the present study between proficiency in English language and the use of databases with EBP knowledge, self-efficacy and practice. Previous studies have considered lack of familiarity with English to be a barrier to EBP implementation among non-English speakers. ${ }^{12,32,33}$ This may be because the majority of up-to-date medical resources are in English. Unfortunately, 
most midwives in the current study had a low understanding of statistical methods; this is important as significant relationships were identified between proficiency in statistics and EBP knowledge, selfefficacy and practice. Numerous EBP studies have reported that an inadequate understanding of statistical terms and difficulties in understanding statistical analysis are two of the most notable barriers to adopting EBP. ${ }^{11,24,34,35}$ Therefore, welldesigned education and training courses focusing on familiarity with the English language, database searching skills and statistical methods are potential approaches to increasing knowledge and facilitating the implementation of EBP among Iranian midwives.

According to Farokhzadian et al., Iranian nurses use more human and print resources than electronic resources to gain information. ${ }^{36}$ Similarly, more than half of the nurses in a study by Yoder et al. utilised physicians or nursing peers as their primary information sources. ${ }^{37}$ Print materials were the most frequently used source of health information in the current study, in particular textbooks and instructions/handouts from the Iranian $\mathrm{MOH}$. Due to the structure, peer review process and legal aspects associated with the publication of these resources, their use in clinical decision-making is justifiable. A significant relationship was observed between use of print resources and EBP knowledge, self-efficacy and practice; this may be due to the continuous updating of printed medical resources. Electronic sources were the second most commonly used source of health information, particularly online tutorials and websites identified via an Internet browser search engine; however, no significant relationships were found between this factor and EBP knowledge, self-efficacy or practice. This may be because browser search engines do not solely provide results from evidencedbased websites. Use of medical e-books and medicinespecific databases was infrequent among midwives in the current study; this may be due to limited Internet access and access to valid databases at home. Midwives in the current study least frequently utilised people as a source of health information; among those who did, colleagues and physicians were the most common information sources. As with electronic sources, no significant relationships were identified between frequency of use of human information sources and EBP knowledge, self-efficacy and practice.

In the present study, significant associations were observed between knowledge of and self-efficacy towards EBP, both of which were associated with practice. Recent quantitative studies have demonstrated that interventions to promote knowledge can improve EBP implementation. ${ }^{24,25}$ Adequate training may therefore be helpful in increasing confidence and engagement in EBP among Iranian midwives; additionally, the findings of the present study may aid hospital managers and policy-makers in the development of strategies to promote EBP in this population. Employing midwives with more advanced academic degrees, providing advanced education programmes-including statistics training-and holding journal clubs to improve midwives' confidence in appraising medical literature are potential strategies to encourage EBP implementation in East Iran.

The results of the present study are subject to certain limitations. First, the findings were based on responses to self-administered questionnaire items and may therefore be inaccurate or biased; data collection using interviews and focus groups might have generated more objective results. Second, since the study was cross-sectional, a causal relationship could not be established. As a result, interventional studies are recommended to confirm these findings. In addition, there is a need for further research to investigate other variables affecting the use of EBP among Iranian midwives.

\section{Conclusion}

The findings of the current study indicate that there is a need to improve EBP knowledge, self-efficacy and practice among Iranian midwives. In addition, there was significantly greater knowledge, practice and self-efficacy in EBP among participants with more advanced academic degrees, those with increased proficiency in English, statistics and the use of databases and among midwives who more frequently used print sources of health information. Consequently, interventions and training that support these factors may help to increase the use of EBP among midwives in East Iran.

\section{CONFLICT OF INTEREST}

The authors declare no conflicts of interest.

\section{FUNDING}

This study was funded by the Torbat-e Heydariyeh University of Medical Sciences (grant number \#132).

\section{References}

1. World Health Organization. Women's health. From: www.who. int/mediacentre/factsheets/fs334/en/ Accessed: Sep 2016.

2. World Health Organization. Trends in maternal mortality: 1990 to 2015. From: www.who.int/reproductivehealth/publications/ monitoring/maternal-mortality-2015/en/ Accessed: Sep 2016. 
3. Hughes RG, Ed. Patient safety and quality: An evidence based handbook for nurses. From: https://archive.ahrq. gov/professionals/clinicians-providers/resources/nursing/ resources/nurseshdbk/nurseshdbk.pdf Accessed: Sep 2016.

4. Ashktorab T, Pashaeypoor SH, Rassouli M, Alavi-Majd A. Nursing students' competencies in evidence-based practice and its related factors. Nurs Midwifery Stud 2015; 4:e23047. doi: $10.17795 / \mathrm{nmsjournal} 23047$.

5. Melnyk BM, Fineout-Overholt E, Gallagher-Ford L, Kaplan L. The state of evidence-based practice in US nurses: Critical implications for nurse leaders and educators. J Nurs Adm 2012; 42:410-17. doi: 10.1097/NNA.0b013e3182664e0a.

6. Stichler JF, Fields W, Kim SC, Brown CE. Faculty knowledge, attitudes, and perceived barriers to teaching evidencebased nursing. J Prof Nurs 2011; 27:92-100. doi: 10.1016/j. profnurs.2010.09.012

7. DeCleene Huber KE, Nichols A, Bowman K, Hershberger J, Marquis J, Murphy T, et al. The correlation between confidence and knowledge of evidence-based practice among occupational therapy students. Open J Occup Ther 2015; 3:5. doi: $10.15453 / 2168-6408.1142$.

8. Greiner AC, Knebel E, Eds. Health Professions Education: A bridge to quality, 1st ed. Washington DC, USA: National Academies Press, 2003. P. 153.

9. Bahammam MA, Linjawi AI. Knowledge, attitude, and barriers towards the use of evidence based practice among senior dental and medical students in western Saudi Arabia. Saudi Med J 2014; 35:1250-6.

10. Kermanshahi S, Parvinian AM. Barriers to implementation of evidence-based care: Viewpoints of nursing staff. Iran J Med Educ 2012; 12:84-92.

11. Majid S, Foo S, Luyt B, Zhang X, Theng YL, Chang YK, et al Adopting evidence-based practice in clinical decision making: Nurses' perceptions, knowledge, and barriers. J Med Libr Assoc 2011; 99:229-36. doi: 10.3163/1536-5050.99.3.010.

12. Weng YH, Kuo KN, Yang CY, Lo HL, Chen C, Chiu YW. Implementation of evidence-based practice across medical, nursing, pharmacological and allied healthcare professionals: A questionnaire survey in nationwide hospital settings. Implement Sci 2013; 8:112. doi: 10.1186/1748-5908-8-112.

13. Mehrdad N, Joolaee S, Joulaee A, Bahrani N. Nursing faculties knowledge and attitude on evidence-based practice. Iran J Nurs Midwifery Res 2012; 17:506-11.

14. Stokke K, Olsen NR, Espehaug B, Nortvedt MW. Evidence based practice beliefs and implementation among nurses: A cross-sectional study. BMC Nurs 2014; 13:8. doi: 10.1186/14726955-13-8.

15. Zhou F, Hao Y, Guo H, Liu H. Attitude, knowledge, and practice on evidence-based nursing among registered nurses in traditional Chinese medicine hospitals: A multiple center cross-sectional survey in China. Evid Based Complement Alternat Med 2016; 2016:5478086. doi: 10.1155/2016/5478086.

16. Karp S. The effects of maternal psychological factors on maternal competence for infant feeding. Thesis, 2008, Vanderbilt University, Nashville, Tennessee, USA.

17. Adib-Hajbaghery M. Factors facilitating and inhibiting evidence-based nursing in Iran. J Adv Nurs 2007; 58:566-75. doi: 10.1111/j.1365-2648.2007.04253.x.

18. Koehn ML, Lehman K. Nurses' perceptions of evidence-based nursing practice. J Adv Nurs 2008; 62:209-15. doi: 10.11 11/j.1365-2648.2007.04589.x.

19. Farokhzadian J, Khajouei R, Ahmadian L. Evaluating factors associated with implementing evidence-based practice in nursing. J Eval Clin Pract 2015; 21:1107-13. doi: 10.1111/jep. 12480.

20. Upton D, Upton P. Development of an evidence-based practice questionnaire for nurses. J Adv Nurs 2006; 53:454-8. doi: 10.1111/j.1365-2648.2006.03739.x.
21. Martis R, Ho JJ, Crowther CA; SEA-ORCHID Study Group. Survey of knowledge and perception on the access to evidencebased practice and clinical practice change among maternal and infant health practitioners in South East Asia. BMC Pregnancy Childbirth 2008; 8:34. doi: 10.1186/1471-2393-8-34.

22. Heiwe S, Kajermo KN, Tyni-Lenné R, Guidetti S, Samuelsson M, Andersson IL, et al. Evidence-based practice: Attitudes, knowledge and behaviour among allied health care professionals. Int J Qual Health Care 2011; 23:198-209. doi: 10.1093/ intqhe/mzq083.

23. Enkin M, Keirse MJ, Neilson J, Crowther C, Duley L, Hodnett E, et al. A Guide to Effective Care in Pregnancy and Childbirth, 3rd ed. Oxford, UK: Oxford University Press, 2000. P. 218.

24. Brown CE, Wickline MA, Ecoff L, Glaser D. Nursing practice, knowledge, attitudes and perceived barriers to evidence-based practice at an academic medical center. J Adv Nurs 2009; 65:371-81. doi: 10.1111/j.1365-2648.2008.04878.x.

25. Shafiei E, Baratimarnani A, Goharinezhad S, Kalhor R, Azmal M. Nurses' perceptions of evidence-based practice: A quantitative study at a teaching hospital in Iran. Med J Islam Repub Iran 2014; 28:135

26. Mohsen MM, Safaan NA, Okby OM. Nurses' perceptions and barriers for adoption of evidence based practice in primary care: Bridging the gap. Am J Nurs Res 2016; 4:25-33. doi: 10.12691/ajnr-4-2-1.

27. Akobeng AK. Principles of evidence based medicine. Arch Dis Child 2005; 90:837-40. doi: 10.1136/adc.2005.071761.

28. Brown CE, Kim SC, Stichler JF, Fields W. Predictors of knowledge, attitudes, use and future use of evidence-based practice among baccalaureate nursing students at two universities. Nurse Educ Today 2010; 30:521-7. doi: 10.1016/j. nedt.2009.10.021.

29. Eberhart A. Quality improvement needs assessment for evidence-based-practice readiness in primary care. Thesis, 2014, Ohio State University, Columbus, Ohio, USA.

30. Eizenberg MM. Implementation of evidence-based nursing practice: Nurses' personal and professional factors? J Adv Nurs 2011; 67:33-42. doi: 10.1111/j.1365-2648.2010.05488.x.

31. Ferguson LM, Day RA. Challenges for new nurses in evidence-based practice. I Nurs Manag 2007; 15:107-13. doi: 10.1111/j.1365-2934.2006.00638.x.

32. Khammarnia M, Haj Mohammadi M, Amani Z, Rezaeian S, Setoodehzadeh F. Barriers to implementation of evidence based practice in Zahedan teaching hospitals, Iran, 2014. Nurs Res Pract 2015; 2015:357140. doi: 10.1155/2015/357140.

33. Chiu YW, Weng YH, Lo HL, Shih YH, Hsu CC, Kuo KN. Comparison of accessing online databases between physicians and nurses in Taiwan. Inform Health Soc Care 2012; 37:230-41. doi: 10.3109/17538157.2012.654842.

34. Hutchinson AM, Johnston L. Bridging the divide: A survey of nurses' opinions regarding barriers to, and facilitators of, research utilization in the practice setting. J Clin Nurs 2004; 13:304-15. doi: 10.1046/j.1365-2702.2003.00865.x.

35. O'Connor S, Pettigrew CM. The barriers perceived to prevent the successful implementation of evidence-based practice by speech and language therapists. Int J Lang Commun Disord 2009; 44:1018-35. doi: 10.1080/13682820802585967.

36. Farokhzadian J, Khajouei R, Ahmadian L. Information seeking and retrieval skills of nurses: Nurses' readiness for evidence based practice in hospitals of a medical university in Iran. Int J Med Inform 2015; 84:570-7. doi: 10.1016/j. ijmedinf.2015.03.008

37. Yoder LH, Kirkley D, McFall DC, Kirksey KM, StalBaum AL, Sellers D. Staff nurses use of research to facilitate evidencebased practice. Am J Nurs 2014; 114:26-37. doi: 10.1097/01. NAJ.0000453753.00894.29. 